\title{
Longitudinal evaluation of liver stiffness and outcomes in patients with chronic hepatitis $C$ before and after short- and long-term IFN-free antiviral treatment
}

Cristina Stasi, Sinan Sadalla, Eleonora Carradori, Monica Monti, Luisa Petraccia, Francesco Madia, Laura Gragnani \& Anna Linda Zignego

To cite this article: Cristina Stasi, Sinan Sadalla, Eleonora Carradori, Monica Monti, Luisa Petraccia, Francesco Madia, Laura Gragnani \& Anna Linda Zignego (2019): Longitudinal evaluation of liver stiffness and outcomes in patients with chronic hepatitis $\mathrm{C}$ before and after short- and long-term IFN-free antiviral treatment, Current Medical Research and Opinion, DOI: 10.1080/03007995.2019.1691517

To link to this article: https://doi.org/10.1080/03007995.2019.1691517

Accepted author version posted online: 08 Nov 2019.

Submit your article to this journal 지

View related articles ¿

View Crossmark data $\asymp$ 
Longitudinal evaluation of liver stiffness and outcomes in patients with chronic hepatitis $\mathrm{C}$ before and after short- and long-term IFN-free antiviral treatment.

Cristina Stasi ${ }^{a}$, Sinan Sadalla ${ }^{a}$, Eleonora Carradori ${ }^{a}$, Monica Monti ${ }^{a}$, Luisa Petraccia $^{a}$, Francesco Madia $^{a}$, Laura Gragnani ${ }^{\text {a }}$, Anna Linda Zignego ${ }^{a}$

a Center for Systemic Manifestations of Hepatitis Viruses (MaSVE), Internal Medicine and Liver Unit, Department of Experimental and Clinical Medicine, Careggi University Hospital, Florence, Italy

Correspondence: Cristina Stasi, Center for Systemic Manifestations of Hepatitis Viruses (MaSVE), Department of Experimental and Clinical Medicine, University of Florence, Florence, Italy, email: cristina.stasi@unifi.it

\section{Transparency}

\section{Declaration of funding}

This work was supported by the Italian Association for Cancer Research (AIRC), Investigator Grant Id 17391, Istituto Toscano Tumori (ITT), and Ente Cassa di Risparmio di Firenze.

\section{Declaration of financial/other relationships}

ALZ has disclosed that she has served on speakers bureaus for Gilead, MSD, and Abbvie and on advisory boards for Abbvie, Gilead, MSD, and BMS. LG has disclosed that she has served on speakers bureaus for Gilead and BMS. CS has disclosed that she has served on speakers bureaus for Gilead and MSD.

\section{Acknowledgements}

The authors would like to thank Helena Ritchie for her English language editing skills. 


\begin{abstract}
BACKGROUND. New direct-acting antiviral drugs can eradicate hepatitis C virus (HCV) infection in over $90 \%$ of patients and can even reduce the risk of complications in advanced fibrosis/cirrhosis. The aims of this study were to evaluate 1) changes in fibrosis during and after antiviral treatment and 2) incidence of hepatocarcinoma and mortality in various fibrosis stages.
\end{abstract}

METHODS. This is a longitudinal monocentric prospective study. Blood and instrumental examinations were evaluated at baseline, at the end of therapy, and 1 and 2 years following treatment.

RESULTS. Two hundred and ninety-six patients with chronic HCV were evaluated, of whom 115 were experienced, 181 were treatment-naïve, and 2 had previous hepatocellular carcinoma (HCC) and were therefore excluded from the study. At baseline, stiffness values were $13.46 \pm 9.97 \mathrm{kPa}$. Out of the $294 \mathrm{HCV}$ patients enrolled, 100 had lymphoproliferative disorders and were evaluated separately. This group of patients showed stiffness values pertaining to the F0-F2 group (mean stiffness values were $6.07 \pm 1.68 \mathrm{kPa}$ ). All other patients showed stiffness values pertaining to the F3-F4 group (mean stiffness values were $17.93 \pm$ 10.23). No statistically significant difference was found between stiffness at baseline compared to the end of treatment (EOT), while significant differences were found between the baseline, 1 year $(p=0.05)$, and 2year follow-ups $(p<0.01)$. Significant differences were found between baseline and EOT, as well as 1 and 2 years after the end of treatment $(p<0.001)$ in the F3-F4 group. Four out of 140 patients with baseline cirrhosis developed HCC during the post-treatment follow-up, 1 of whom died.

CONCLUSIONS. Non-invasive methods provide important prognostic information, particularly concerning the observed regression of fibrosis and could be extremely useful for monitoring patients with long life expectancies after direct-acting antiviral treatment.

Keywords: fibrosis; elastography; chronic hepatitis C; direct-acting antiviral drugs 


\section{Introduction}

New direct-acting antiviral drugs (DAAs) can eradicate hepatitis C virus (HCV) infection in over $90 \%$ of patients. According to recent studies, the use of DAAs reduces the risk of complications even in advanced fibrosis [1].

The evolution of chronic hepatitis $C$ into liver cirrhosis is correlated with an extensive accumulation of the extracellular matrix, leading to the formation of large amounts of fibrotic tissue. This tissue is initially concentrated in periportal areas and, in later stages, completely surrounds the nodules of regenerating hepatocytes. The progressive increase of the fibrotic matrix contributes to both vascular disturbances (favouring the development of irreversible portal hypertension) and microenvironmental changes that facilitate the occurrence of hepatocellular carcinoma (HCC) [2].

Liver cirrhosis is a well-recognised negative prognostic factor not only due to the risk of complications, including HCC, but also concerning its response to antiviral therapies. Clinical practice guidelines for chronic hepatitis therapy recommend evaluating liver fibrosis to support decision-making, treatment timing, and the proper follow-up of patients after antiviral treatment [3].

Several drugs are currently available to treat HCV-infected patients, and cure rates have continuously improved over the last decade. However, further studies are still needed to assess longitudinal changes in hepatic fibrosis and outcomes in patients after DAA treatment, particularly those with severe liver damage at baseline [2]. Despite being an invasive procedure, liver biopsy has long been considered the "gold standard" for the evaluation of fibrosis. However, several studies have shown that non-invasive methods are becoming increasingly precise in either positively identifying or excluding liver fibrosis, thus drastically reducing the need for liver biopsy $[4,5]$.

Although increasing evidence for the prognostic value of non-invasive hepatic fibrosis assessment has been reported, so far only a few studies have evaluated the regression of fibrosis or the incidence in long-term occurrence of HCC following DAA-based antiviral treatment. It has been suggested that this information could radically change patients' prognoses and improve our understanding of the short-term and long-term effects of current antiviral therapies [6]. Therefore, the objectives of this study were to evaluate 1) the changes in fibrosis during and after DAA-based antiviral treatment, and 2) the incidence of HCC and mortality in the various stages of baseline fibrosis.

\section{PATIENTS AND METHODS \\ Patients}

This is a longitudinal monocentric prospective study. Patients were consecutively enrolled at the outpatient clinic in the Hepatology Centre MASVE, Department of Clinical and experimental Medicine, University of Florence, according to the following inclusion criteria: 1) presence of detectable HCV-RNA; 2) absence of antiviral or immunosuppressive therapies during the 6 months prior to enrollment; 3 ) exclusion of Child-C cirrhosis; 4) absence of HCC, acute viral hepatitis ( $<6$ months), co-infection with hepatitis B virus (HBsAg positive and/or HBcAb positive) or human immunodeficiency virus, metabolic liver disease, autoimmune hepatitis, vascular disease of the liver, and biliary tract disorders; 5 ) the absence of alcohol consumption or use of hepatotoxic drugs; and 6) the absence of clinical conditions potentially affecting transient elastography (FibroScan ${ }^{\circledast}$ ) (e.g. ascites or cardiac failure) or when this technique is contraindicated (e.g. pregnancy).

The blood and instrumental examinations necessary for the study were evaluated at baseline, at the end of therapy, and at 1 and 2 years after the end of treatment.

The diagnosis of liver cirrhosis was performed according to standard (histologic, clinical, and ultrasound) criteria $[5,6]$. 
follows:

1. Patients with cirrhosis in Child class A or B and/or HCC with complete response to surgical or locoregional therapies are not candidates for liver transplantation as liver disease significantly affects prognosis.

2. Post-liver transplantation (LT) recurrent HCV and advanced graft fibrosis.

3. Chronic hepatitis with severe HCV-related extrahepatic manifestations (cryoglobulinemic syndrome with organ damage, B-cell lymphoproliferative syndromes).

4. Chronic hepatitis $\mathrm{C}$ with fibrosis stage METAVIR F3 (or corresponding Ishak stage).

5. On the waiting list for liver transplantation with cirrhosis MELD $<25$ and/or HCC in accordance with the Milan criteria with a waiting time of at least 2 months.

6. Chronic hepatitis after solid organ transplantation (not liver) or bone marrow, with fibrosis METAVIR F2 (or corresponding Ishak stage).

7. Chronic hepatitis with fibrosis stage METAVIR F0-F2 (or corresponding Ishak stage) (only for simeprevir).

The nature of the study was explained to the patients, who provided written informed consent before entrance into the study, in accordance with the Declaration of Helsinki (revised in Edinburgh, 2000).

\section{Clinical-virological evaluation}

HCV-related lymphoproliferative disorders. All enrolled patients underwent a structured evaluation for the most frequent extrahepatic HCV disorders, mixed cryoglobulinemic syndrome (MCS) $[8,9]$ and lymphoma [10].

MCS was diagnosed according to previously described criteria [11-13]. Serum cryoglobulin levels and characterisation, levels of complement fractions, rheumatoid factor, and autoantibodies were evaluated as described [11-13]. Lymphoma diagnosis was performed according to Ferri et al. [10] after specialised evaluation.

Liver cirrhosis. Upper endoscopy was performed in all cirrhotic patients, and assessment of the severity of cirrhosis was performed using Child-Pugh and MELD scores, together with evaluation of the main complications.

The Child-Pugh score was used to assess liver cirrhosis severity [14].

A disease severity scoring system was designed to improve organ allocation in transplantation based on the severity of liver disease rather than the length of time on the waiting list, and was used to assess end stage liver disease for adults [15].

Antiviral therapy follow-up. When therapy was indicated for 8 weeks, biochemical and HCV-RNA parameters were evaluated at baseline, at 1, 2, and 4 weeks, and at 8 weeks (end of treatment: EOT) after the start of treatment. When therapy was indicated for 12 or 16 weeks, an evaluation was also performed at 12 or 16 weeks (EOT), respectively. Liver ultrasound was performed at least every 24 weeks in cirrhotic patients. Sustained virologic response (SVR) was evaluated at 12 and 24 weeks after the EOT (SVR12 and SVR24).

Liver fibrosis assessment. The assessment of liver fibrosis was performed at baseline, at EOT, 1 year after the EOT, and 2 years after the EOT. An ultrasound examination was performed every 24 weeks in F3-F4 patients.

Liver stiffness was evaluated using FibroScan ${ }^{\circledR}$, according to the manufacturer's instructions. In all patients, elastography was performed after 6 hours of fasting.

Procedures were considered reliable only after 10 successful acquisitions, with a success rate of at least 
$60 \%$, and an interquartile range (IQR) of less than $30 \%$ of the average value.

\section{Statistical analysis}

All results were expressed as mean \pm standard deviation. The numerical comparison of continuous data was performed using the Wilcoxon rank sum test applied to two-sample. Statistical significance was set at a value of $p<0.05$. Statistical analyses were obtained using statistical software Stata 12 (College Station, TX, USA) and SPSS v18 (SPSS, Inc., Chicago, IL, USA).

\section{RESULTS \\ Baseline}

The study was conducted from January 2015 to July 2018. Two hundred and ninety-six patients with chronic liver disease were evaluated, aged between 89 and 24 years, of whom 167 (56.4\%) were women and 129 were (43.6\%) men. $168(56.8 \%)$ had genotype $1 \mathrm{~b}, 37(12.5 \%)$ had genotype 1a; $42(14.2 \%)$ had genotype $2 ; 35(11.8 \%)$ had genotype $3 ; 13(4.4 \%)$ had genotype $4 ; 1(0.3 \%)$ had genotypes $1 \mathrm{a}+1 \mathrm{~b}$.

Out of 296 patients, 116 (39.2\%) patients were treatment-experienced, 180 (60.8\%) were treatment-naïve, and 2 of these patients had previous HCC and were excluded from the study. One hundred patients (33.8\%) had MCS, 6 of whom with non-Hodgkin's lymphoma (LNH), and 1 patient with multiple myeloma.

The clinical and instrumental parameters of the study population are shown in Table 1.

At baseline, the stiffness values were $13.46 \pm 9.97 \mathrm{kPa}$. Of the total $294 \mathrm{HCV}$ patients, 100 lymphoproliferative disorder patients were evaluated separately. This group of patients showed stiffness values pertaining to the F0-F2 group (mean stiffness values were $6.07 \pm 1.68 \mathrm{kPa}$ ). All other patients showed stiffness values pertaining to the F3-F4 group (mean stiffness values were $17.93 \pm 10.23$ ). Severity of liver cirrhosis is shown in table 2.

Enrolled patients were eligible for treatment according to the Italian Medicines Agency prioritisation criteria for DAAs as follows: 140 patients were treated for criterion 1; 100 for criterion 3; 3 for criterion 5; and 51 for criterion 4.

Prescribed DAA Treatment combinations were as follows: daclatasvir+sofosbuvirtribavirin in 76 patients, ledipasvir+sofosbuvir in 133 patients, simeprevir+sofosbuvirtribavirin in 19 patients, and paritaprevir, ombitasvir, and ritonavir in 13 patients and paritaprevir, ombitasvir, ritonavir and dasabuvir in 53 patients. In 137 patients, DAAs were associated with the use of ribavirin. One hundred and fifty-two patients were treated for 12 weeks; 124 for 24 weeks; and 18 were treated for 8 weeks.

\section{Longitudinal evaluation}

Out of 296 patients treated with DAAs, 3 (1\%) patients discontinued treatment (all three patients discontinued therapy due to poor compliance), 292 (98.6\%) achieved SVR12 and SVR24, 1 (0.3\%) patient had a virological relapse after the end of treatment with ledipasvir, but analysis of HCV viral resistance revealed NS5A-resistant variants. These 4 patients who did not achieve a SVR were excluded from longitudinal evaluation of liver stiffness.

At EOT, stiffness values were $11.58 \pm 10.21 \mathrm{kPa}$; 1 year after treatment, they were $10.36 \pm 8.57$; and $9.36 \pm$ 5.142 years after. No significant difference was found between baseline stiffness values compared to the EOT $(p=0.29)$, while statistically significant differences were found between the baseline, 1-year $(p=0.05)$, and 2-year follow-ups $(p<0.01)$. None of the patients experienced a worsening of fibrosis or absence of liver stiffness regression after therapy.

When the patients were divided into groups with patients with lymphoproliferative disorders (FO-F2) and the main group (F3-F4), no significant differences in liver stiffness values were found between the baseline and EOT, or after 1 and 2 years from the end of treatment in the F0-F2 group. On the contrary, significant 
differences were observed in the F3-F4 group between both the baseline and EOT, and at 1 and 2 years after EOT $(p<0.001)$. Stiffness values are shown in Table 3. Concerning liver function tests, significant differences were found between the baseline AST levels and those at EOT and at 1 and 2 years after the EOT $(p<0.001)$; between baseline ALT levels and those at the EOT and at the 1 year and 2 year follow-up after the EOT ( $p<0.001$ ); and between baseline gamma GT levels, those at the EOT, and 1 year and 2 year follow-up after the EOT $(p<0.001)$.

Out of 294 patients, 4 developed HCC (1.4\%), 1 of whom died (table 4).

None of the cirrhotic patients developed cirrhosis decompensation during the post-treatment follow-up.

\section{Discussion}

Due to the recent introduction of DAAs, few studies have been conducted for the longitudinal evaluation of liver fibrosis and outcomes in patients with chronic hepatitis $C$ at baseline, and after a short- and longterm follow-up after IFN-free antiviral treatment. This study demonstrated that a significant reduction in stiffness values was observed at different time points during treatment for periods of time ranging from 1 year to a maximum of 2 years when compared to pre-treatment stiffness values. On the contrary, at the EOT, only AST and ALT values were significantly different. This confirms a substantial reduction in necroinflammation at the end of treatment and a certain degree of fibrosis regression after the EOT. According to our results, Bachofner et al. [16] showed a rapid decrease in liver stiffness values that was in concordance with regression of the validated fibrosis scores FIB-4 and APRI, suggesting an investigation into whether this indicates a real regression of fibrosis or merely a resolution of chronic liver inflammation.

Moreover, the significant regression of liver stiffness in patients with F3-F4 compared to patients with F0F2 strongly suggests that this outcome is particularly pronounced in patients with progressive liver fibrosis.

According to our study, the results of Tada et al. [17] suggest that early improvement of liver stiffness starts during the administration of DAAs and is particularly pronounced in patients with progressive liver fibrosis.

Several studies [18-22] were performed in the era of Interferon (IFN)-based therapy to investigate the potential utility of elastography in assessing the longitudinal regression or progression of the disease. These studies provided information on the impact of successful antiviral treatment 2 to 3 years after the EOT. Our previous studies $[23,24]$ have shown that pre-treatment liver stiffness may be useful for predicting a response to treatment in patients treated with either IFN plus ribavirin, or interferon plus ribavirin plus boceprevir, or IFN plus ribavirin plus telaprevir [24].

New evidence [25-28] suggests liver stiffness improvement after DAA treatment. The present study shows data obtained at time points never before investigated ( 2 years after treatment) in a large cohort of Italian patients, and is substantially in accordance with and reinforces previous studies.

In particular, this study shows that the extent of liver tissue fibrosis is an important negative predictor for the incidence of HCC. In fact, all patients who developed HCC after therapy presented with advanced liver disease with signs of portal hypertension at baseline. Consequently, the evaluation of liver fibrosis before treatment in patients with a SVR12 and SVR24 may be a useful instrument to assess long-term prognosis. Recently, Rosso et al. [29] examined a total of 5172 medical records of chronic hepatitis $C$ patients enrolled from 1990 to 2011 and they assessed the impact of metabolic cofactors on the occurrence of clinical events during a follow-up in a group of chronic hepatitis $C$ patients who were long-term responders to IFN-based therapy. The authors demonstrated that hepatic steatosis at baseline may predispose to the development of cardiovascular events and type 2 diabetes during follow-ups.

In our study, we have not collected data on steatosis and/or metabolic syndrome, because the absence of metabolic liver disease was one of the inclusion criteria. Notwithstanding this, on the basis of the data of Rosso et al. [29], further studies are needed to evaluate the complex role played by hepatic steatosis in 
patients with metabolic syndrome in the absence of viral infection. In particular, these studies could evaluate the effective risk of cardiovascular events, glucose abnormalities (impaired fasting glucose and type 2 diabetes) and dyslipidemia at baseline, and over a period time during and after patients' treatment with the emerging therapies for non-alcoholic fatty liver disease and non-alcoholic steatohepatitis. The main limitation is the non-uniform distribution of patients for fibrosis stages, as enrollment was affected by the previous Italian Drug Agency's prioritisation of antiviral treatment criteria. In particular, patients with fibrosis stages F3/F4 at the time of the study were more common and were treated with DAAs compared to $<F 3$ due to the prioritisation of antiviral treatment criteria by the Italian Drug Agency in 2015 and 2016. However, the enrollment of patients in a referral centre for HCV-related extrahepatic diseases allowed for the enrollment of patients with severe HCV-related extrahepatic manifestations, but with less advanced fibrosis.

In conclusion, the obtained data provide more information about both the regression of advanced liver fibrosis after DAA-related treatment, and shows that non-invasive methods may have a significant impact in monitoring regression/progression of liver fibrosis in patients with long life expectancies after DAA treatment. 


\section{References}

1. El-Sherif O, Jiang ZG, Tapper EB, Huang KC, Zhong A, Osinusi A, Charlton M, Manns M, Afdhal NH, Mukamal K, McHutchison J, Brainard DM, Terrault N, Curry MP. Baseline Factors Associated With Improvements in Decompensated Cirrhosis After Direct-Acting Antiviral Therapy for Hepatitis C Virus Infection. Gastroenterology. 2018 Jun;154(8):2111-2121.e8

2. Caviglia GP, Rosso C, Fagoonee S, Saracco GM, Pellicano R. Liver fibrosis: the 2017 state of art. Panminerva Med. 2017;59:320-331

3. European Association for Study of Liver. EASL Recommendations on Treatment of Hepatitis C 2018. J Hepatol. 2018 Apr 9. pii: S0168-8278(18)31968-8

4. Stasi C, Milani S. Non-invasive assessment of liver fibrosis: Between prediction/prevention of outcomes and costeffectiveness. World J Gastroenterol 2016; 22: 1711-1720

5. Stasi C, Arena U, Vizzutti F, Zignego AL, Monti M, Laffi G, Corti G, Pinzani M. Transient elastography for the assessment of liver fibrosis in patients with chronic viral hepatitis: The missing tool? Dig Liv Dis 2009; 41: 863-866.

6. Stasi C, Milani S. Evolving strategies for liver fibrosis staging: Non-invasive assessment. World J Gastroenterol. 2017 Jan 14;23(2):191-196.

7. Agenzia Italiana del Farmaco. L'AIFA pubblica il nuovo Algoritmo per la terapia dell'Epatite C cronica. 2015. Available at: http://www.agenziafarmaco.gov.it/it/content/pubblicato-il-nuovoalgoritmolaterapia-dell'epatite-c-cronica [Last accessed March 25, 2015]

8. Petrarca A, Rigacci L, Caini P, Colagrande S, Romagnoli P, Vizzutti F, Arena U, Giannini C, Monti M, Montalto P, Matucci-Cerinic M, Bosi A, Laffi G, Zignego AL. Safety and efficacy of rituximab in patients with hepatitis $C$ virus-related mixed cryoglobulinemia and severe liver disease. Blood 2010, 116:335342.

9. de Vita S, Quartuccio L, Isola M, Mazzaro C, Scaini P, Lenzi M, Campanini M, Naclerio C, Tavoni A, Pietrogrande M, Ferri C, Mascia MT, Masolini P, Zabotti A, Maset M, Roccatello D, Zignego AL, Pioltelli P, Gabrielli A, Filippini D, Perrella O, Migliaresi S, Galli M, Bombardieri S, Monti G: A randomized controlled trial of rituximab for the treatment of severe cryoglobulinemic vasculitis. Arthritis Rheum 2012, 64:843-853.

10. Ferri C, Pileri S, Zignego AL. Hepatitis C virus infection and non-Hodgkin's lymphoma. In: Geodert J, ed. Infectious Causes of Cancer: Targets for Intervention. Totowa, NJ: Humana Press;2000: 349-368

11.Zignego AL, Giannelli F, Marrocchi ME, Mazzocca A, Ferri C, Giannini C, Monti M, Caini P, Villa GL, Laffi G, Gentilini P: T $(14 ; 18)$ translocation in chronic hepatitis C virus infection. Hepatology 2000, 31:474479.

12.Zignego AL, Ferri C, Giannini C, Monti M, la Civita L, Careccia G, Longombardo G, Lombardini F, Bombardieri S, Gentilini P: Hepatitis $C$ virus genotype analysis in patients with type II mixed cryoglobulinemia. Ann Intern Med 1996, 124:31-34.

13. Andreone P, Zignego AL, Cursaro C, Gramenzi A, Gherlinzoni F, Fiorino S, Giannini C, Boni P, Sabattini E, Pileri S, Tura S, Bernardi M: Prevalence of monoclonal gammopathies in patients with hepatitis $C$ virus infection. Ann Intern Med 1998, 129:294-298.

14. Pugh RNH, Murray-Lyon LM, Dawson JL, Pietroni MC Williams R. Transection of the esophagus for bleeding oesophageal varices. Br J Surg 1973; 60: 646-9.

15. Kamath PS, Wiesner RH, Malinchoc M, Kremers W, Therneau TM, Kosberg CL, et al. A model to predict survival in patients with end-stage liver disease. Hepatology. 2001;33:464-470.

16. Bachofner JA, Valli PV, Kröger A, Bergamin I, Künzler P, Baserga A, Braun D, Seifert B, Moncsek A, Fehr J, Semela D, Magenta L, Müllhaupt B, Terziroli Beretta-Piccoli B, Mertens JC. Direct antiviral agent treatment of chronic hepatitis $C$ results in rapid regression of transient elastography and fibrosis markers fibrosis-4 score and aspartate aminotransferase-platelet ratio index. Liver Int. 2017;37:369-376 
17. Tada $T$, Kumada T, Toyoda H, Mizuno K, Sone $Y$, Kataoka S, Hashinokuchi S. Improvement of liver stiffness in patients with hepatitis $C$ virus infection who received direct-acting antiviral therapy and achieved sustained virological response. J Gastroenterol Hepatol. 2017;32:1982-1988

18. Ogawa $\mathrm{E}$, Furusyo $\mathrm{N}$, Toyoda $\mathrm{K}$, et al. The longitudinal quantitative assessment by transient elastography of chronic hepatitis $C$ patients treated with pegylated interferon alpha- $2 b$ and ribavirin. Antiviral Research 2009;83:127-34.

19. Arima $Y$, Kawabe $N$, Hashimoto $S$, et al. Reduction of liver stiffness by interferon treatment in the patients with chronic hepatitis C. Hepatol Res 2010;40:383-92.

20. Macías J, del Valle J, Rivero A, et al. Changes in liver stiffness in patients with chronic hepatitis $C$ with and without HIV co-infection treated with pegylated interferon plus ribavirin. J Antimicrob Chemother 2010;65:2204-11.

21. Wang JH, Changchien CS, Hung $\mathrm{CH}$, et al. Liver stiffness decrease after effective antiviral therapy in patients with chronic hepatitis C: longitudinal study using FibroScan. J Gastroenterol Hepatol 2010;25:964-9.

22. Martinez SM, Foucher J, Combis JM, et al. Longitudinal liver stiffness assessment in patients with chronic hepatitis C undergoing antiviral therapy. PLoS ONE 2012;7:e47715.

23. Stasi C, Arena U, Zignego AL, Corti G, Monti M, Triboli E, Pellegrini E, Renzo S, Leoncini L, Marra F, Laffi $G$, Milani S, Pinzani M. Longitudinal assessment of liver stiffness in patients undergoing antiviral treatment for hepatitis C. Dig Liver Dis. 2013;45:840-3.

24. Stasi C, Piluso A, Arena U, Salomoni E, Montalto P, Monti M, Boldrini B, Corti G, Marra F, Laffi G, Milani $S$, Zignego AL. Evaluation of the prognostic value of liver stiffness in patients with hepatitis $C$ virus treated with triple or dual antiviral therapy: A prospective pilot study. World J Gastroenterol. 2015 Mar 14;21(10):3013-9.

25. Dolmazashvili E, Abutidze A, Chkhartishvili N, Karchava M, Sharvadze L, Tsertsvadze T. Regression of liver fibrosis over a 24-week period after completing direct-acting antiviral therapy in patients with chronic hepatitis $C$ receiving care within the national hepatitis $C$ elimination program in Georgia: results of hepatology clinic HEPA experience. Eur J Gastroenterol Hepatol. 2017; 29:1223-1230

26. Persico M, Rosato V, Aglitti A, Precone D, Corrado M, De Luna A, Morisco F, Camera S, Federico A, Dallio M, Claar E, Caporaso N, Masarone M. Sustained virological response by direct antiviral agents in HCV leads to an early and significant improvement of liver fibrosis. Antivir Ther. 2018;23:129-138

27. Chan J, Gogela N, Zheng H, Lammert S, Ajayi T, Fricker Z, Kim AY, Robbins GK, Chung RT. Direct-Acting Antiviral Therapy for Chronic HCV Infection Results in Liver Stiffness Regression Over 12 Months Posttreatment. Dig Dis Sci. 2018;63:486-492

28. Kobayashi N, lijima H, Tada T, Kumada T, Yoshida M, Aoki T, Nishimura T, Nakano C, Takata R, Yoh K, Ishii A, Takashima T, Sakai Y, Aizawa N, Nishikawa H, Ikeda N, Iwata Y, Enomoto H, Hirota S, Fujimoto J, Nishiguchi $\mathrm{S}$. Changes in liver stiffness and steatosis among patients with hepatitis $\mathrm{C}$ virus infection who received direct-acting antiviral therapy and achieved sustained virological response. Eur J Gastroenterol Hepatol. 2018;30:546-551.

29. Rosso C, Caviglia GP, Ciruolo M, Ciancio A, Younes R, Olivero A, Giordanino C, Troshina G, Abate ML, Rizzetto M, Pellicano R, Saracco GM, Bugianesi E, Smedile A. Clinical outcomes in chronic hepatitis $C$ long-term responders to pre-direct antiviral agents: a single-center retrospective study. Minerva Med. 2019;110:401-409. 
Table 1: Clinical and laboratory parameters in the study population before antiviral treatment

\begin{tabular}{l|l|l} 
Parameter & Value & Normal Range \\
Male gender, $\mathrm{n}(\%)$ & $129(43.6 \%)$ & $150-400$ \\
Platelet count $\left(10^{9} / \mathrm{L}\right)$ & $171.5 \pm 67.60$ & $0.1-1.3$ \\
Total Bilirubin (mg/dl) & $0.8 \pm 0.52$ & $10-40$ \\
Y-GT (U/L) & $65.0 \pm 59.6$ & $5-40$ \\
AST (U/L) & $22.09 \pm 8.9$ & $5-40$ \\
ALT (U/L) & $27.7 \pm 11.7$ & $30-120$ \\
Alkaline phosphatase & $104.3 \pm 81.95$ & $0.9-1.8 \mathrm{~g} / \mathrm{L}$ \\
C3 & $0.9 \pm 0.2$ & $0.1-0.4 \mathrm{~g} / \mathrm{L}$ \\
C4 & $0.14 \pm 0.09$ & $20 \mathrm{IU} / \mathrm{mL}$ \\
Rheumatoid factor & $117.0 \pm 432.021$ & \\
Stiffness kPa (baseline) & $13.4 \pm 9.97$ & \\
\hline Results are expressed as mean \pm standard deviation (SD). Values of liver stiffness are \\
expressed as mean \pm interquartile range (IQR)
\end{tabular}

Abbreviations: $\gamma$-GT, gamma glutamyl-transpeptidase; AST, aspartate transaminase;

ALT, alanine transaminase 


\begin{tabular}{|ccc}
\hline \multicolumn{1}{|c}{ Table 2. Clinical and laboratory parameters of the cirrhotic patients, stratified by the Child-Pugh score } \\
\hline & $\begin{array}{c}\text { Child-Pugh class A } \\
(\mathbf{n}=108) \\
\text { median (min/max) }\end{array}$ & $\begin{array}{c}\text { Child-Pugh class B } \\
(\mathbf{n}=32) \\
\text { median }(\min / \mathrm{max})\end{array}$ \\
\hline Total bilirubin (mg/dl) & 0.8 & 1.4 \\
$(0.5-1.7)$ & $(0.4-2.0)$ \\
\hline Albumin (g/dl) & 3.7 & 3.2 \\
$(3.5-4.7)$ & $(2.4-3.6)$ \\
\hline International normalized ratio & 1.4 & 1.3 \\
(sec.) & $(1.3-1.5)$ & $(0.5-2.0)$ \\
\hline Creatinine (mg/dL) & 0.8 & 0.9 \\
\hline Sodium (mmol/L) & $(0.7-2.3)$ & $(0.5-2.4)$ \\
\hline
\end{tabular}

\begin{tabular}{|c|c|c|c|c|}
\hline & & Baseline & $10=$ & 2 year follow-up \\
\hline $\begin{array}{l}\text { Cirrhotic } \\
\text { Patients }\end{array}$ & $\begin{array}{c}\text { Child } \\
\text { Pugh/MELD }\end{array}$ & Genotype & Treatment & $\begin{array}{c}\text { Child } \\
\text { Pugh/MELD }\end{array}$ \\
\hline $\begin{array}{c}\text { N.1, } 84 \text { years, } \\
\text { male }\end{array}$ & $\mathrm{A} 5 / 7$ & $1 b$ & $\begin{array}{c}\text { Ledipasvir for } 24 \\
\text { weeks }\end{array}$ & $A 5 / 6$ \\
\hline $\begin{array}{c}\text { N. 2, } 82 \text { years, } \\
\text { male }\end{array}$ & $\mathrm{A} 5 / 12$ & $a / c$ & $\begin{array}{c}\text { Sofosbuvir and } \\
\text { Daclatasvir for } \\
12 \text { weeks }\end{array}$ & $A 6 / 14$ \\
\hline $\begin{array}{c}\text { N.3, } 57 \text { years, } \\
\text { male }\end{array}$ & B7/ 12 & $1 \mathrm{a}$ & $\begin{array}{l}\text { Sofosbuvir + } \\
\text { Daclatasvir }+ \\
\text { ribavirin for } 24 \\
\text { weeks }\end{array}$ & B7/ 12 \\
\hline $\begin{array}{c}\text { N.4, } 66 \text { years, } \\
\text { female }\end{array}$ & $A 6 / 13$ & $1 b$ & $\begin{array}{c}\text { Sofosbuvir + } \\
\text { Daclatasvir }+ \\
\text { Ribavirin for } 12 \\
\text { weeks }\end{array}$ & A5/ 7 \\
\hline
\end{tabular}


Table 4. Longitudinal evaluation of liver stiffness values

\begin{tabular}{|c|c|c|c|c|}
\hline & Baseline & $\begin{array}{l}\text { End of } \\
\text { treatment }\end{array}$ & $\begin{array}{l}1 \text { year after } \\
\text { EOT }\end{array}$ & $\begin{array}{l}2 \text { years after } \\
\text { EOT }\end{array}$ \\
\hline Stiffness $(\mathrm{kPa})$ in & $6.07 \pm 1.68$ & $5.21 \pm 1.13$ & $5.18 \pm 0.94$ & $5.01 \pm 1.20$ \\
\hline
\end{tabular}

Stiffness (kPa) in all $\quad 17.93 \pm 10.24 \quad 12.69 \pm 10.89 \quad 11.31 \pm 8.96 \quad 10.48 \pm 5.17$ other patients

Abbreviations: EOT, end of treatment 